\title{
Training Virtually Virtual
}

\author{
Workplace E-Learning for Automotive Assembly Operators \\ http://dx.doi.org/10.3991/ijac.v5i3.2201
}

\author{
Lennart Malmsköld $^{1,2}$, Roland Örtengren ${ }^{1}$, Lars Svensson ${ }^{3}$ \\ 1 Chalmers University of Technology, Sweden \\ 2 Volvo Group Trucks Technology, Gothenburg, Sweden \\ ${ }^{3}$ University West, Trollhattan Sweden
}

\begin{abstract}
This paper reports from a longitudinal study of a Swedish manufacturer in the automotive industry, where a series of studies have explored the potential and limitations of computer-based training of assembly operators. The study is focusing on two supplementing sets of target variables - operators' attitudes and the quality output from operators in real production. Starting with small-scale studies where proof-of-concept for virtual training is established, the research moves on to comparative studies where different computer-based learning models are contrasted and evaluated. The research design ends with large-scale field experiments assessing the effects of computer-based training in terms of quality output. The results clearly demonstrate that computer-based training, when integrated with training of standardized work procedures, outperforms traditional methods for operator training, regardless of the content and the context of the assembly operation. The findings of the study are synthesized into a design framework for virtual training where cognitive and craftsmanship training is contrasted to the learning of product, process, sequence and finesse of assembly.
\end{abstract}

Index Terms-Virtual Assembly Training, Automotive Operator Training, Lean Production, Standardized Work.

\section{INTRODUCTION}

The rationale that drive initiatives of workplace elearning ranges from the desire of reducing educational costs, through ambitions to create training environments where learners can operate without running the risk of causing serious harm to people or materials, to the necessity of bridging geographical, cultural or organizational distances. Similarly, the objectives of an elearning initiative varies from the ambition to socialize newcomers into an existing work practice, to the need for preparing an organization to adapt to a future where new practices have to evolve [1].

In the automotive industry, the primary driving factor for launching e-learning initiatives stems from the fact that newly designed vehicles only exist in the virtual world right up to the point of the start of production. Car manufacturers have to strive for excellent quality performance, to be more flexible regarding production volumes and a high frequency of introducing new models. Furthermore, launches of a new vehicle has requirements where increased equipment reuse level, less prototype vehicles and decreased ramp-up time (the period from production starts until it has reached full production rate) are characteristics. Usage of an existing production system means that introduction of new vehicles in the plant is done by mixing the new vehicles into the normal production flow during the launch period [2].

Earlier research shows some promising results for the potential of virtual training in manufacturing industry. Virtual reality (VR) systems has proven to be successful in areas such as welding [3], machining [4],[5] and object assembly [6],[7]. However, the positive results in prior research have yet to be proven in the context of full-scale realistic production.

\section{THE AUTOMOTIVE CONTEXT}

In automotive industries, the development process is based on the usage of math-based tools with the consequence that prototype material such as prototype vehicles are no longer produced at all or only in a limited number. To support the work with math-based tools in the development process, special virtual gates also exist in the00 development plan. Prior the gates, virtual builds are performed by Manufacturing Engineering, where complete vehicles are virtually assessed to verify that the design meets the requirements raised from a manufacturing point of view. In figure 1 some example from a virtual build is seen. Through this information is created which is possible to reuse for training purposes of the production organization in later stages.

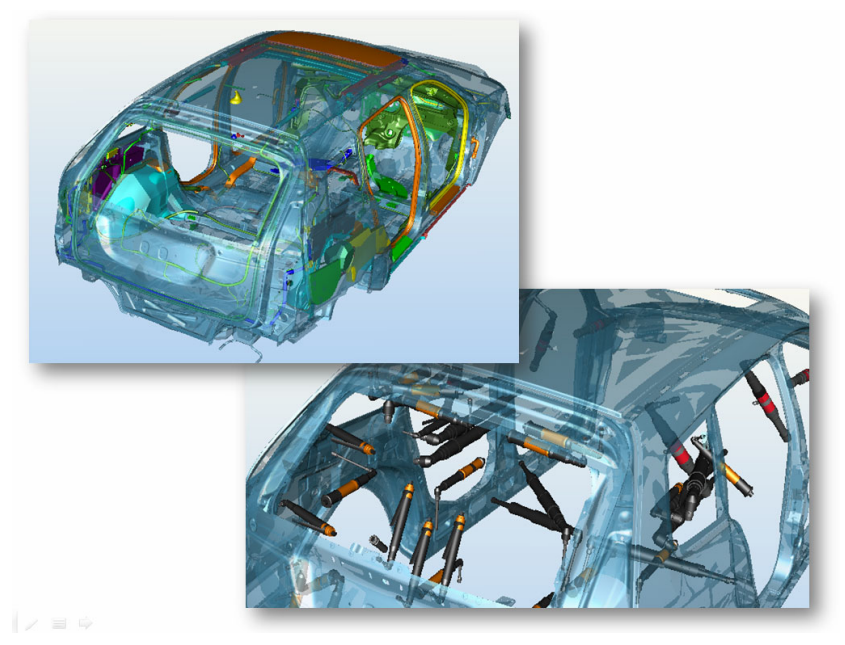

Figure 1. Material created by the ME organization and used during a virtual build 
Training of assembly operators can differ in details but is in general based on the principle that a master teaches an apprentice. In the Toyota Production System, [8] which is the model for how many automotive companies are running their production the responsibility for the training and coaching of Team Members rests on the Team Leaders. Normally a Team Leader coaches a team containing 5-6 operators.

Standardized Work is another important concept included in TPS [9]. The development of standardized work is based on the use of standardized work documents. One of them, the "Standard Operation Sheet (SOS)", presented in Figure 2, comprises a detailed description of the sequence in which several operations (work elements) should be performed. Each line in the table presented in the SOS is representing a work element.

Another important document is the "Job Element Sheet" (JES), illustrated in Figure 3. It describes each work element shown in the SOS in detail by means of a list of important work steps. Furthermore, any key points and reasons connected to the operation are presented.

The training within TPS is named Job Instruction Training (JIT) and the training has its origin in the TWI (Training within Industry) concept [10]. The training is divided into four steps.The first step concerns familiarizing the Team Member with the work. The second step is the demonstration of the operation, where the JES and the components and tools employed in the specific operation is used as training material. The third step is a try-out, performed by the Team Member and repeated until he/she masters the operation. The fourth and final step of the training session is a follow and feedback from the Team Leader

Training prior to and during pre-series production has been the main target for this work and exemplified by the conditions at the studied automotive company, is this activity performed through a gradual integration of new vehicles into existing production.

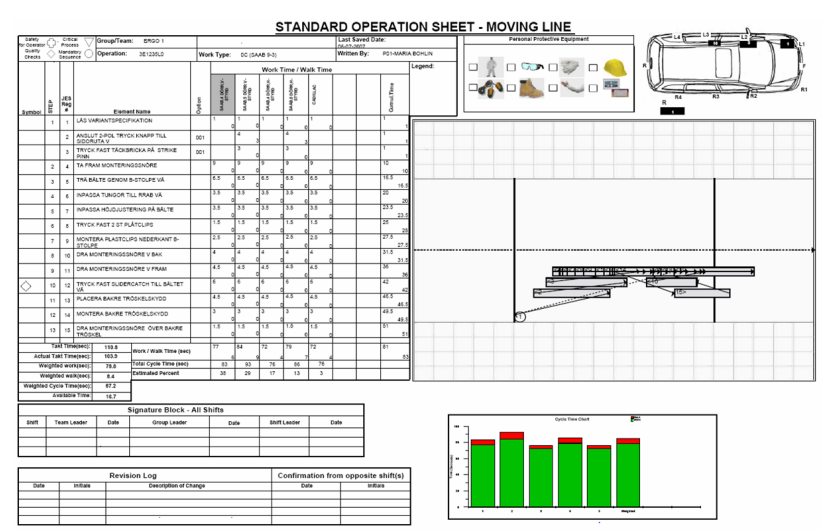

Figure 2. Example of a SOS from the studied automotive company

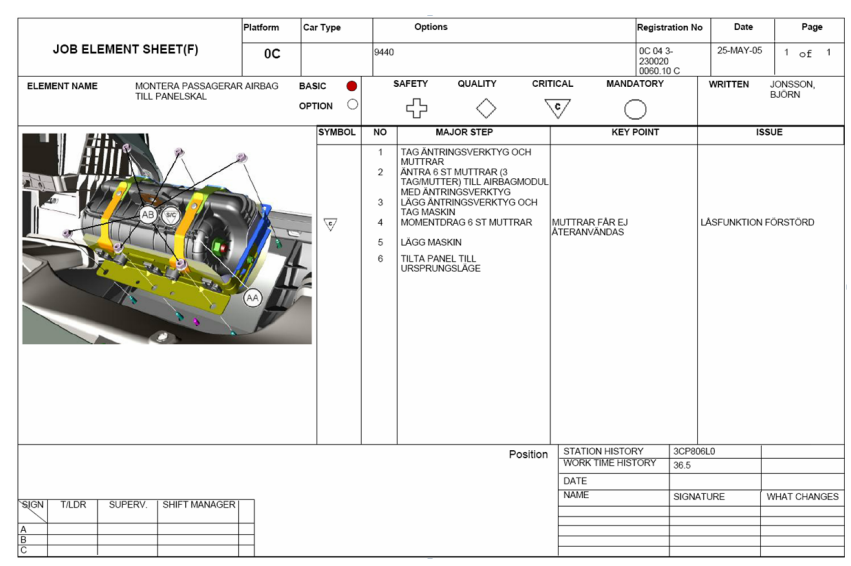

Figure 3. Example of a JES

In this setup, the vehicles in the first pre-series batch are spread over time so that the interval between them is often hours or initially even days. During succeeding preseries batches, the intervals gradually decrease. The Team Leader can therefore perform all operations on the first new vehicles by following them through all stations within the team's working area. By so, doing he/she also demonstrates the operations to the Team Member at each station. Ideally the JIT training, which is performed on a separate vehicle off-line, should have started prior to the first batch and historically this has generally been the case. Due to cost and prototype reductions, the trend is that JIT training before the start of pre-series production is very limited or non-existent and is instead initiated during or after the first pre-series batch.

\section{METHOD}

In view of the exploratory and empirical nature of the problem domain, a case study approach appeared to be a natural choice [11]. The major benefit of adopting a case study approach is that the problem is studied in an authentic setting with operators performing the learning activities as an integrated part of their work. Primary data of a quantitative character were studied in combination with qualitative data. The latter approach was mainly used in the first studies due to the relatively small groups of test subjects. Therefore, semi-structured interviews provided important complementary information for understanding which factors and relations are relevant when doing virtual training. The used analysis process for the interviews was based on the method described by [12].

In the two final studies the main conclusions were drawn from data collected in existing quality follow up systems and from performance data derived from the virtual training tool. Semi-structured interviews and observations were used to complement the collected data.

The methodological approach in the studies can be described as data triangulation. This was applied in this work to combine data from several sources such as observations, interviews and quantitative data [13],[14]. In applied research the balance between rigour and relevance must be considered in the research design [15]. 
The research presented in this work is the result of a unique opportunity to perform studies in a real production context, including scenarios during new vehicle model launches where assembly was performed by experienced operators. Thus, its relevance is very high. A high level of rigour is ensured by the fact that the research design incorporates test and control groups, a combination of small and large scale studies in addition to a longitudinal design.

\section{OVERVIEW OF THE STUDIES}

In the present studies, the purpose was to measure and understand the impact of virtual training, especially during the pre-series period, prior new vehicle Start of Production (SOP)

A schematic view and a timeline are presented in Figure 4. The studies in part A provided an understanding of the impact of computer-based training compared to traditional training, the results of which were documented in [16]. A period of planning for the case studies then followed. Interviews and tests took place, mainly with the team of expert operators called Pilot Team. The output from this period, Part B and the results from [16] constituted the foundation for how the following studies ,in Part C, were performed. Input to [17] was also defined in this intermediate period, since the first draft of the framework (which constituted the major content of [17]) was formulated at this point. The framework presented in [17] constituted the basis for the field studies reported in [21] and [22].

\section{CONTENT AND RESULTS OF THE STUDIES}

In Part $A$ the objective of the studies was to compare virtual (computer-based) training with traditional training. The study comprised operators divided into two groups; a test group and a reference group. The test group used the desktop based commercial VR tool, Vizendo, see further description in [16]. The reference group received traditional, instructor based training. All activities took place prior to the start of pre-series production and during the first period of a new vehicle product launch. Assembly performance was compared between the two groups during the first production on the assembly line. A view of the virtual training and the corresponding assembly line is shown in Figure 5.

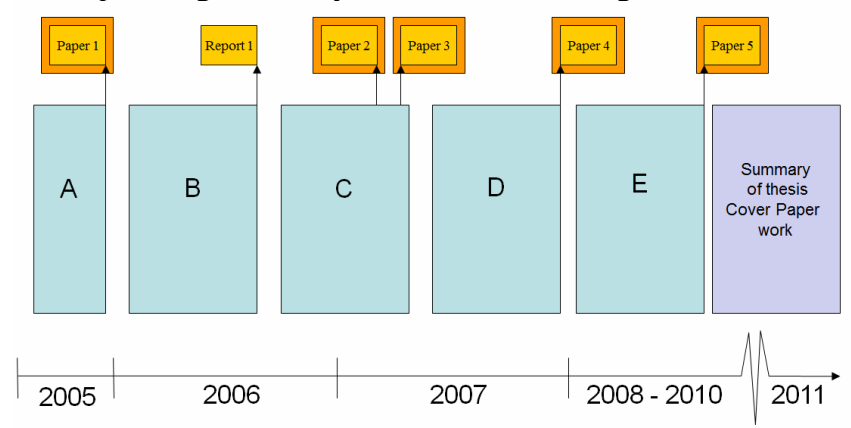

Figure 4. An overview of the different parts of the work

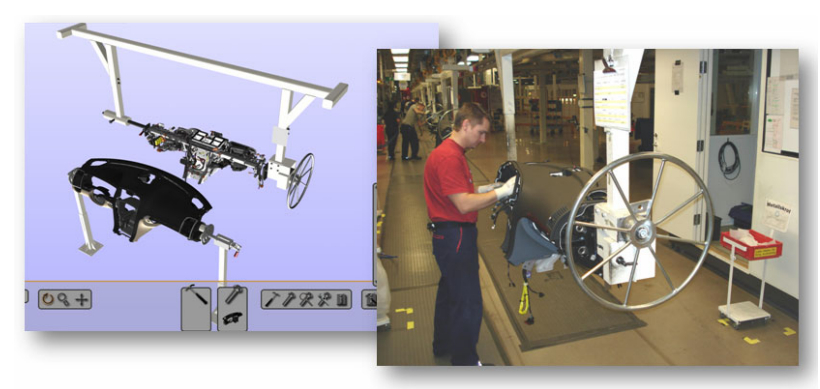

Figure 5. Screenshot from training software and a photo from one of the assembly stations

The results indicated that virtual training, combined with motor skill training gained from the production of vehicle batches in the pre-series phase, could provide operators with similar assembly skills as those who receive traditional training.

Part $\mathrm{C}$ of the research contained several studies and the work in part $C$ resulted in two papers ([18] and [17]).

A framework including knowledge phases in assembly training was presented. The framework can be used for understanding the learning processes in this specific area but also for understanding operator training learning trajectories as well as providing a theoretical foundation for the design of novel techno-pedagogical virtual training models [17].

In the process of learning new operations, two basic types of learning can be identified: (a) Cognitive Learning and (b) Associative and Autonomous Learning.

When studying the learning of a single operation or task, cognitive learning is initially dominant, but after some trials more focus is placed on performing the operation in a correct way. At this stage the training of movement patterns is dominant [19], [20]. The case studies reported in [16] and [18] all demonstrated these learning types, but since the work of an operator at an assembly station alternates depending on which type of vehicle is to be assembled, training of all combinations of operations is necessary. In addition, quality requirements can influence operations, and other aspects may have to be taken into account to fulfil legal or customer requirements. The case studies as well as the discussions and interviews with the instructors in the assembly plant highlighted the different phases of learning. Using this as a base, the framework was derived with the four different knowledge phases of Cognitive Learning and Associative and Autonomous Learning. The knowledge phases can be seen as more or less chronological steps in the learning process during training. The framework and the knowledge phases are shown in Figure 6. The framework can be seen as a development of the work by [19] and [20] and constitutes an elucidation model for this type of training as well as a useful tool for framing the design space of virtual training software for application within the specific area.

The studies that constituted the basis for [18] were carried out based on the findings in [16], combined with input 
from the expert operators (Pilot Team) gathered in Part B. The focus was on cognitive learning processes and mainly covered the first two cognitive dimensions of the framework (the product and process phases). The accomplished studies took place during the introduction of new vehicle variants and constituted the basis for the exploration of the two different models, Expert-based Learning and System-based Learning (in the following called the Expert Model and the System Model). Their potential as a preparatory method for making cognitive learning more effective was assessed.

The two learning models are similar in many respects. Both use 3D data to describe new job content and are intended to provide a complete visual presentation of components to be assembled in the intended assembly sequence. A central constituent of the Expert Model is an active dialogue between different groups in order to facilitate knowledge transfer (Figure 7).

The basic idea is to transfer knowledge from the experts to the novices in three steps (Figure 7). However, as in this situation the novice has experience of similar tasks and specific conditions at the station where the operations are performed, the activity can to some extent be seen as mutual. In this model, the virtual tool, VisMockUp [18] is used as visualization support for the Team Leader when he/she describes the content of the new operations in a dialogue with the Team Member. In addition, support documents that describe each operation or job in detail are employed.

In the System Model the new operational content is learnt by self-study. The operators train by interacting with the computer in a self-contained environment (Figure 8). In the studies the tool used in the System Model was Vizendo [18].

\begin{tabular}{|c|c|c|}
\hline Knowledge phases & $\begin{array}{l}\text { Cognitive Training } \\
\text { (Computer-based training) }\end{array}$ & $\begin{array}{l}\text { Associative \& Autonomous } \\
\text { training } \\
\text { (Training with physical } \\
\text { components) }\end{array}$ \\
\hline Product & $\begin{array}{l}\text { Product shape, special features, } \\
\text { differences between variants, } \\
\text { fasteners used }\end{array}$ & $\begin{array}{l}\text { How to handle, i.e. grip } \\
\text { positions }\end{array}$ \\
\hline Process & $\begin{array}{l}\text { Interface parts, "third hand", } \\
\text { placement in car, necessary } \\
\text { toolsiequipment, their functionality } \\
\text { and wherehow they interact with the } \\
\text { partis), quality and safety demands, } \\
\text { tightening sequence demands }\end{array}$ & $\begin{array}{l}\text { Fitting in, adjustment, } \\
\text { assembly path, tool path, } \\
\text { handling of tool }\end{array}$ \\
\hline Sequence & $\begin{array}{l}\text { Knowledge of valid sequences for } \\
\text { variants at different stations }\end{array}$ & $\begin{array}{l}\text { Performance of operations in } \\
\text { correct sequence with the } \\
\text { right quantity within the } \\
\text { scheduled cycle time }\end{array}$ \\
\hline Finesse & $\begin{array}{l}\text { Knowledge of key points and } \\
\text { reasons, i.e. issues to bear in mind } \\
\text { when pertorming the operations and } \\
\text { why it is important to perform them in } \\
\text { a certain way }\end{array}$ & $\begin{array}{l}\text { Performance of operations in } \\
\text { correct sequence with the } \\
\text { right quantity within the } \\
\text { scheduled cycle time } \\
\text { and including finesse }\end{array}$ \\
\hline
\end{tabular}

Figure 6. Knowledge phases and their connectedness in a design framework.

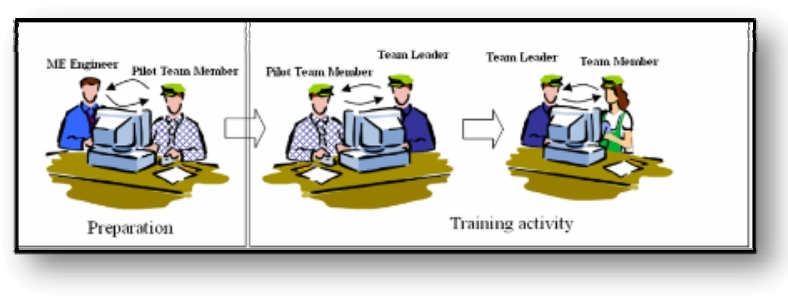

Figure 7. Knowledge transfer in the Expert Model

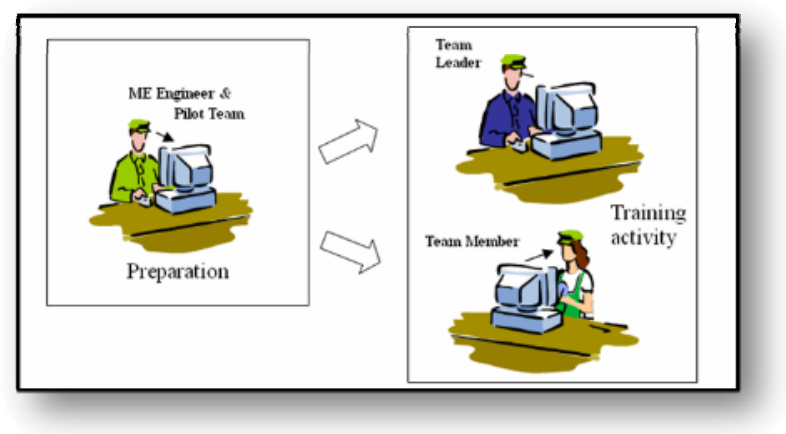

Figure 8. Knowledge transfer in the System Model

The quantitaitve results [18] and the qualitative results from the interviews [18] indicated that the Expert Model was better than the System Model for preparatory training, since the dialogue between the Team Leader and Team Member supported by the viszualisation tool (VisMockUp) and process documents (JES/SOS) facilitated superior preparation for the new operations. This also was confirmed by the interviews [18].

In part D (Figure 4) the framework seen in Figure 6 constituted the base for the accomplished studies. The two parts of cognitive learning; assembly sequence and finesse, received special focus. The aim was to understand whether or not computer-based training could improve the operators' learning and through this improve their quality output. Several studies or field experiments were conducted in two different areas of the assembly line. The studies were carried out at a period when many operations were relocated to new stations due to a change in line speed and therefore training for new operational sequences was required. In the studies, new developed training software called SeQualia was used. SeQualia, was created due to the need to enable operators to engage in some form of self-study training using JIT information as a complement to existing training. It was considered important to include gaming features in the software, thus incorporating an 'edutainment' dimension, i.e. combining education and entertainment elements. The assembly information, presented in a similar layout to the existing process document, SOS and JES was retrieved from a continuously updated JES/SOS database (Figure 9). 


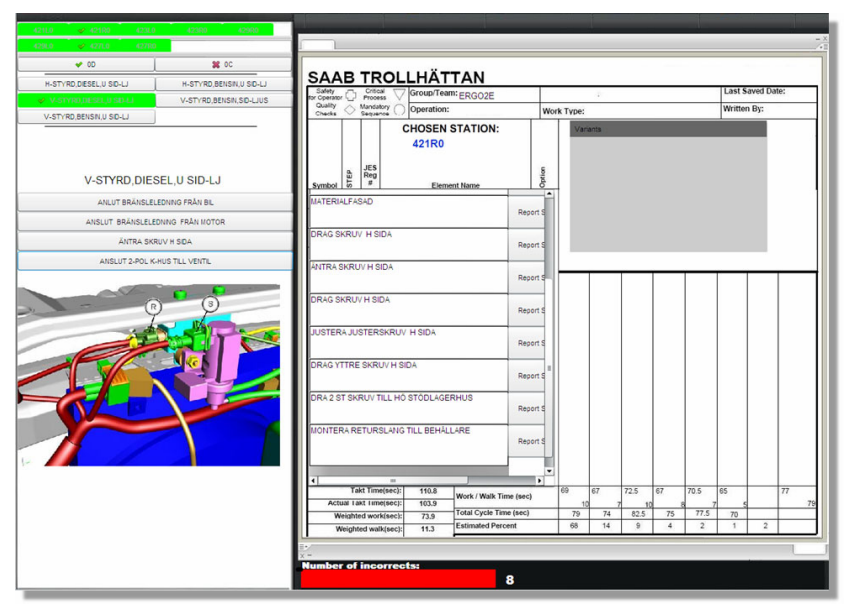

Figure 9. Main user interface in SeQualia, with a similar layout to a SOS.

The major task for the operator is to create the correct SOS for a selected station, model and variant. This is accomplished through correct selection of one of four randomly presented JES alternatives. If the operator's choice is incorrect, an error message appears on screen and the red penalty bar at the bottom, which indicates the accumulated number of incorrect answers in the training session, increases by one unit. This procedure continues until the whole SOS is completed.

As a means of tracking improvements related to computer-based training, the two studies were set up as field experiments [15] with a test and a reference group. The test and reference groups belonged to different shifts in the respective line areas and contained 4-5 teams, each comprising one leader and five operators. In order to address the research questions, quality performance was compared between the reference operator groups that had regular in-work training and test groups where some of the in-work training was replaced by individual computer-based training.

In both studies the subjects (Team Members) received an individual introduction and demonstration of the software. Each session lasted for approx. 30 minutes and all Team Members selected one or several stations and variants for training. The evaluation in both studies was conducted by tracking quality losses through from the existing quality data system and by means of interviews.

The first study, in part D, named Study A, was carried out on a part of the main line, including 17 stations with 17 operators [21]. The operators in the test group had an average total virtual training time of 2.6 hours each. Interviews were performed with 6 operators and 3 Team Leaders.

The second study, named Study B, took place in a subassembly line area where doors were assembled. The line area had 28 stations and all 28 operators were included in the study. During the study period the operators had an average total training time of 6.1 hours each.

Similar to Study A, data from the quality follow-up system were tracked, but more specific analyses were conducted based on the different types of quality notation. At the end of the test period, interviews were conducted with 6 operators and 2 Team Leaders.

The results of both studies revealed an overall improvement in quality output for the test group compared with the reference group. The results from Study B were categorized into different fault types and in several cases a direct connection between the computerbased training process instructions (Key Points and Reasons in the JES) and the quality loss levels was seen. One of the quality problems studied in detail was leakage, which is especially connected to doors and water incorrectly drained from the door. Many Key Points and Reasons were related to this type of problem and fault type, which could therefore be connected to operator knowledge of Key Points and Reasons. Figure 10 illustrates the frequency of the "Leakage" fault type for both groups. The average improvement for the Test Group between the Reference and the Study period was a decrease from 6.5 down to $3.7(-42 \%)$ and for the Reference Group a decrease from an average of 4.6 to 4.4 $(-5 \%)$.

The results of Studies A and B demonstrated an improvement in quality output for the test groups compared to the reference groups. Furthermore, the operators described benefits of using the training application as gaining a better understanding and knowledge of the job content [21].

Part E, (Figure 4) contained several field experiments, which evaluated how large-scale virtual operational sequence training and related quality information can support operators’ assembly performance.

All field experiments were conducted during the launch of a new vehicle. In the first field experiment (Study $\alpha$ ), learning progress and quality performance were compared between reference groups of operators whose members only had regular training and a test group of operators where some of the regular training was replaced by individual computer-based training. The total number of subjects was approximately 80 and included a test group and two separate reference groups with 10-15 operators in each.

The experiment was conducted during one week of intensive training where the test group had a session of virtual training every day.

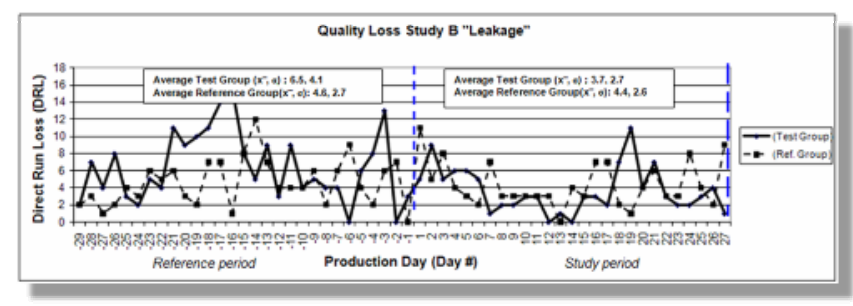

Figure 10. Loss levels regarding "Leakage” for both groups in study B 
On the final day the virtual training tool (SeQualia) was used to measure learning progress in the test and reference groups respectively (Figure 11). In addition to quantitative measures of operator learning progress due to the virtual training, operator-related output quality during the subsequent production weeks and questionnaires were used to evaluate the effects of virtual training.

The results of the study (Figure 12) clearly demonstrated that computer-based training outperforms traditional training in terms of reading JES and SOS documents. The mean value of average error per operator (AEO) after four to five training sessions was substantially reduced. Since the reference group was relatively small, it was of interest to obtain data that could be used to compare two similar groups.

An additional reference group comprising 14 operators selected from another line area was established, thus permitting enhanced understanding of the impact of virtual training [22].

In Study $\beta$, a large field experiment was conducted covering the sub-plants from body-in-white to general assembly. Focus was on validating the results of Study $\alpha$ on a larger scale and approximately 360 operators each received four twenty-minute training sessions over the course of four training days, which occurred during a production stop. The training activity focused on Key Points and Reasons for each JES and all operational content of the two stations in the operators' own work area was included in the training sessions. The SeQualia training tool was used. Also Study $\beta$ ( Figure 13) showed substantial learning progress: From around 6 errors in initial mean values for each Plant Team (Average error /operator, AEO), the levels dropped to below one error per operator and session.

The quantitative results from the two field experiments ( $\alpha$ and $\beta$ ) combined with the positive attitudes expressed by the operators and their Team Leaders indicate that this is an effective way to train operators during new vehicle launches in automotive production [22].

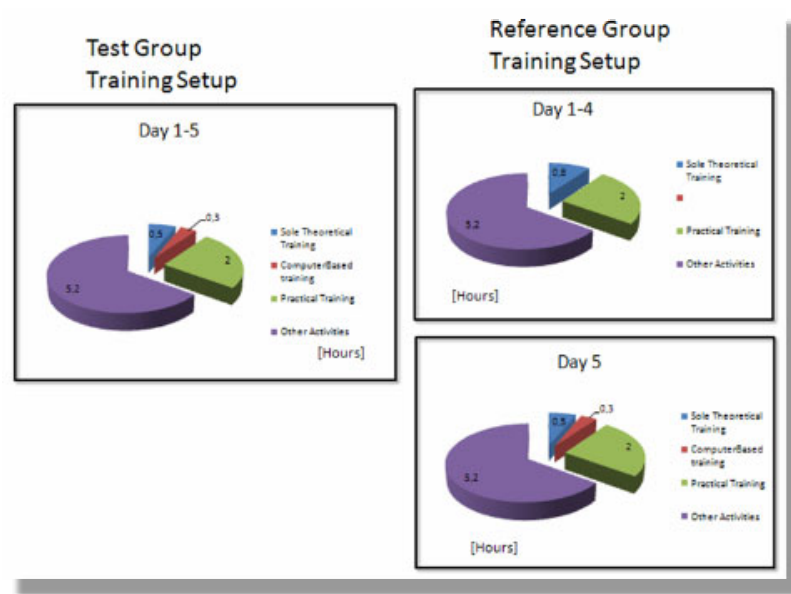

Figure 11. Training Setup for the different groups during the field

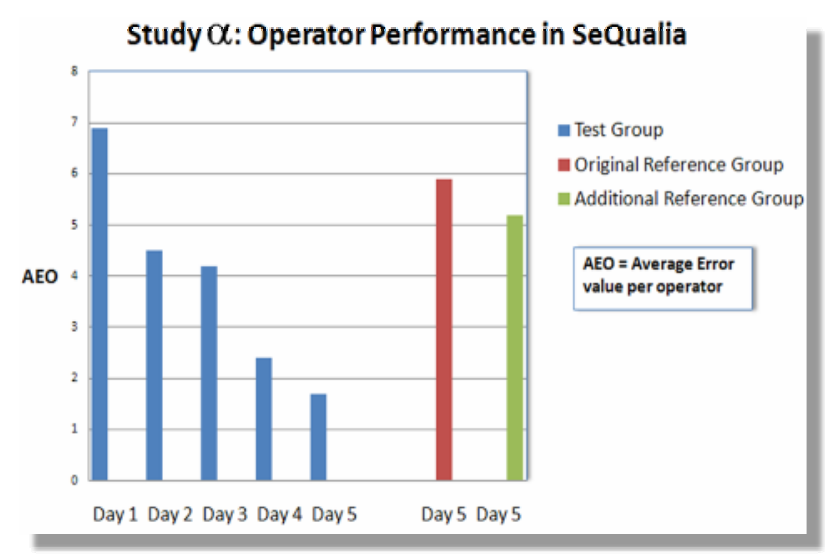

Figure 12. Operator performances in SeQualia, Study $\alpha$

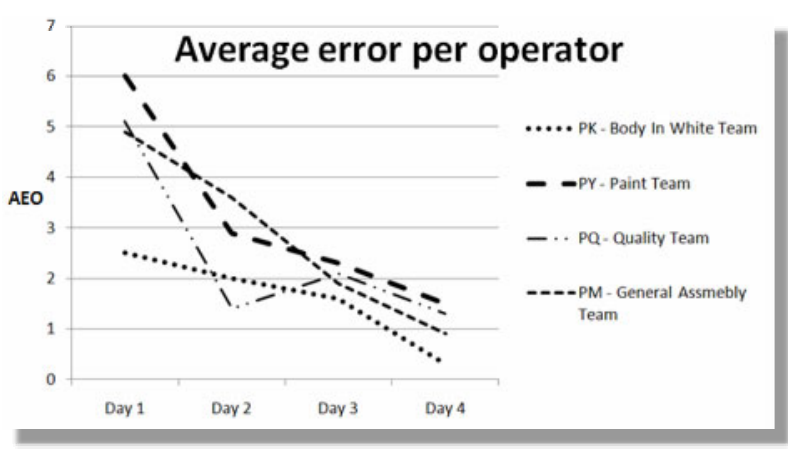

Figure 13. Progress in theoretical skill for the four Plant Teams in Study $\beta$.

\section{A DUAL STEP CONCEPT FOR VIRTUAL TRAINING - A CONTRIBUTION TO RESEARCH AND PRACTICE}

Based on the case study results from all Parts, a Dual Step Concept for virtual training is proposed and constitutes the final contribution to research and practice from this work. A cornerstone of the concept is the framework presented in Figure 6. The concept is designed to take account of the special conditions that exist in the automotive industry, although the framework is more general and can serve as a support in other research areas connected to virtual training.

There are two cognitive knowledge phases of interest when introducing new operations for skilled operators: Product and Process aspects. Understanding of the job content is the main requirement in preparatory training. The combination of operations, the Assembly sequence, is also of interest, but initially an understanding of operation station location and general knowledge of the sequence is sufficient. This content is the basis of the initial preparatory training activity, Step 1 . Here, 3D-models are a necessary input, as no or very limited access to physical components exists. In the next step intensive training of complete sequences and finesse issues for the different variants at each station are of more interest. This occurs when the final sequence has been established, i.e. in the 
later stages of pre-series period. Here the need for 3D models for training purposes is limited, as the operators already have good basic knowledge of the job content. Furthermore, Figures 14 and 15 highlight the relevant performance areas for virtual training and the proposed timing of each step in the training activity.

Virtual training is an area where many concepts proposed in the literature have a basis in different types of 3D model-based self-study applications. This work explores several types of approach. The use of existing training methods, combined with the utilisation of 3D models was one of the approaches. Another was to reuse existing process documents such as SOS and JES for virtual training. The reason for exploring these alternative approaches was the interest in finding a successful virtual training concept, where reuse of existing information in true "lean spirit" is advantageous and a clear link to established training methods exists.

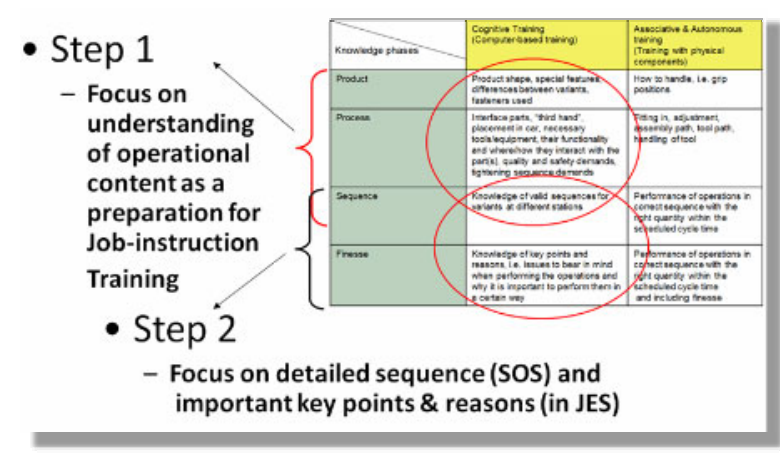

Figure 14. Progress in theoretical skill for the teams in Study $\beta$.

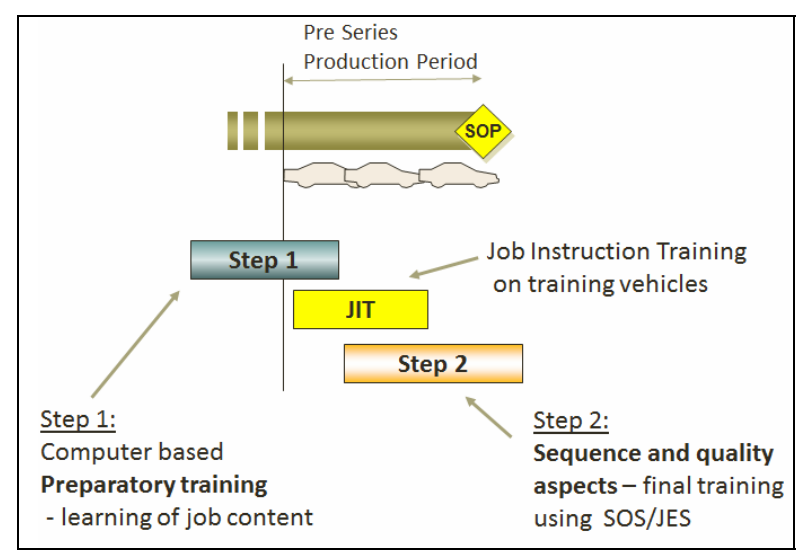

Figure 15. The timing of training steps 1 and 2 in the Dual Step virtual training Concept

\section{CONCLUSIONS}

This work has aimed at understanding if and how virtual training can serve as an effective alternative to traditional training and thereby support operators, especially when launching new vehicles.

The conclusions are:

i. A virtual training tool is an effective initial training method and can replace traditional instructor-based training in certain areas.

Using a desktop-based training tool with focus on cognitive training was found to be effective for preparing experienced operators before the introduction of new vehicles.

ii. Virtual preparatory training of assembly operators can be performed in an efficient manner by using the Expert-based Learning Model defined and explored.

The major reasons are:

- The opportunity for dialogue between the Team Leader and Team Member during initial training,

- Enhanced training for Team Leaders during the training period

iii. Assembly quality performance can be substantially improved through interactive virtual training

- The work has clearly demonstrated that computer-based training outperforms traditional training based on the reading of assembly instructions (JES and SOS documents). Both the theoretical learning rate and the quality performance were improved by the training.

The four knowledge phases in the defined framework are supported by the results of the case studies and have formed the basis for the proposed Dual Step Concept for virtual training.

The presented concept has the following parts:

A) Initial Virtual Preparatory training (Step 1) Focus is on understanding of product and process. This training, which is based on the Expert Learning Model, is a preparation for the first pre-production vehicles on the assembly line. It serves as training for Team Leaders and Expert Operators, who act as teachers during the pre-production stage. 


\section{B) Craftsmanship Training - JIT}

Initial practical training on training vehicles using JIT and continued by gaining experience of the production of pre-series vehicles on the assembly line.

\section{C) Virtual Sequence \& Finesse Training (Step 2).} Here the focus is on drilling assembly sequences and quality-related issues (finesse). This training comprises interactive self-studies using the System Learning Model.

\section{REFERENCES}

[1] L. Svensson "Inter-regional cooperation on Work-Integrated elearning” , Journal of Workplace Learning, 16 (8), 2004

[2] M. Goyal, S. Netessine, T. Randall, ”Deployment of manufacturing flexibility: an empirical analysis of the North American automotive industry”, 2006, unpublished, mgoyal@rhsmith.umd.edu.

[3] K. Fast, T. Gifford, R. Yancey, "Virtual Training for Welding”. Proceedings of the 3rd IEEE and ACM International Symposium on Mixed and Augmented Reality. Washington DC 2004, 298-299. ISBN 0-7695-2191-6 http://dx.doi.org/10.1109/ISMAR.2004.65

[4] A. Balijepalli, T. Kesavadas, "Value-Additon of Haptics in Operator Training for Complex Machining Tasks”, Journal of Computing and Information Science in Engineering, Volume 4, Issue 2, pp. 91-97, 2004 http://dx.doi.org/10.1115/1.1739240

[5] A. Wasfy,T. Wasfy, A. Noor,'Intelligent virtual environment for process training", Advances in Engineering Software, 35, pp: 337355, 2004 http://dx.doi.org/10.1016/j.advengsoft.2004.04.005

[6] J. Dawei, A. Bhatti, S. Nahavandi,. "Design and evaluation of a haptically enable virtual environment for object assembly training”, Haptic Audio visual Environments and Games, 2009. HAVE 2009. IEEE International Workshop on, 7-8 Nov. 2009

[7] T. Gutiérrez, J. Rodríguez, Y. Vélaz, S. Casado, A. Suescu, and E. Sánchez, "IMA-VR: A Multimodal Virtual Training System for Skills Transfer in Industrial Maintenance and Assembly Tasks.” Conference proceedings, 19th IEEE International Symposium on Robot and Human Interactive Communication, 2010

[8] J. K. Liker, D. Meier, The Toyota Way Field book: A Practical Guide for Implementing Toyota's 4Ps, 2006 New York: McGrawHill.

[9] D A. Dinero, Training Within Industry: The Foundation of Lean. Productivity Press, New York, NY, 2005

[10] P. Graupp, RJ. Wrona, THE TWI WORKBOOK: Essential Skills of Supervisors, Productivity Press ISBN:1563273152, 2006

[11] R. K. Yin, Case study research: design and methods 3. Ed. Thousand Oaks: Sage Publications, cop.,2003
[12] G. McCracken, The long interview: Newbury Park, Calif.: Sage, ISBN 0-8039-3352-5, 1988

[13] N.K. Denzin, The research act: A theoretical introduction to sociological methods. Chicago: Aldine, 1970.

[14] M.Q. Patton, Qualitative evaluation and research methods (2 ${ }^{\text {nd }}$ ed.). Newbury Park, CA: Sage, 1990

[15] P. Järvinen, On research methods, Tampere: Opinpaja, 1999

[16] L. Malmsköld, R. Örtengren, B. Carlson, P. Nylén, “Instructor based training versus computer based training - A comparative study”, Journal of Educational Technology Systems, 35 (4),20062007, pp. 457-478

[17] L. Malmsköld, R. Örtengren, B. Carlson, L. Svensson, "Virtual Training - towards a design framework”, G. Richards (Ed.), Proceedings of World Conference on E-Learning in Corporate, Government, Healthcare, and Higher Education 2007 (pp. 62996307). Chesapeake, VA: AACE.

[18] L. Malmsköld, R. Örtengren, B. Carlson, L. Svensson, "Preparatory virtual training of assembly operators - an explorative study of different learning models" Swedish Production Symposium (SPS) 2007, Conference proceedings

[19] P.M. Fitts, M.I. Posner Human performance, Belmont, Calif., Brooks/Cole Pub. Co. 1967 ISBN 0-13-445247-x

[20] E.M. Dar-El, K. Ayas, I. Gilad, “A dual-phase mode for the individual learning process in industrial tasks”. IIE Transactions, 27, 1995, pp 265-271. http://dx.doi.org/10.1080/074081795089 $\underline{36740}$

[21] L. Malmsköld, R. Örtengren, B. Carlson, L. Svensson, “Computer Based Training for Automotive Assembly Operators - a Potential Way to Improve Quality Output" In conference proceedings, Interactive Technologies, 2008, Society for Applied Learning Technology

[22] L. Malmsköld, R. Örtengren, L. Svensson, "Improved quality output through computer based training - an automotive assembly field study", unpublished

\section{AUTHORS}

L. Malmsköld, Dr was at SAAB Automobile Trollhattan, Sweden. He is now with Volvo Group Trucks Technologies, Process Development \& Manufacturing Engineering, 40508 Gothenburg, Sweden (e-mail: Lennart.Malmskold@volvo.com)

R. Örtengren, Professor, is with Department of Product and Production Development, Chalmers University of Technology, SE-412 96 Gothenburg (e-mail: Roland.Ortengren@chalmers.se)

L. Svensson, Ass. Professor is with Department Economics and IT, University West, SE-461 86 Trollhattan (e-mail: Lars.Svensson@hv.se)

This article is an extended version of a paper presented at the conference ICELW2012, held June 2012, at Columbia University, in New York, NY, USA. Received 19 july 2012. Published as resubmitted by the authors 5 August 2012. 